\section{Percutaneous Removal of a Displaced Inferior Vena Cava Filter Using a Loop-Wire Technique and Lead-Extraction Sheaths}

Koki Fujimori, MD; Ayako Okada, MD, PhD; Hiroaki Tabata, MD; Morio Shoda, MD, PhD; Koichiro Kuwahara, MD, PhD

A 59-year-old woman who presented with an inferior vena cava (IVC) filter (TrapEase, Cordis, USA) that had displaced into the left common iliac vein during thrombectomy using a Fogarty catheter was referred after 2 failed retrieval procedures. 3D computed tomography demonstrated that the IVC filter was located at the bifurcation of the common iliac vein (Figure A). We decided to attempt a 3 rd retrieval procedure. Because we could not catch the distal end of the filter that was embedded into the vessel wall, we used a loop-wire technique. ${ }^{1} \mathrm{~A}$ guidewire inserted into a pig-tail catheter was advanced from the left groin and turned so that it went through the filter. A lasso-type snare (LASSOS, OSYPKA, Germany) was inserted from the same sheath as the guidewire to grasp its distal end (Figure C), and then both ends of the guidewire were exposed at the groin from the same sheath. A telescopic mechanical sheath set (Cook, USA) was advanced toward the filter through the twofold guidewire and was used to dissect the adhesion tissue by rotating the telescopic sheath (Figure C, Supplementary Movie). The loopwire technique and specialized lead extraction tools are useful, even for a difficult retrieval of a displaced IVC filter, which might otherwise require open surgery. ${ }^{2}$

\section{Disclosure}

A.O. is affiliated with an endowed section sponsored by Medtronic, Biotronik, BostonScientific, Abbott, JLL. K.K. is a member of Circulation Journal's Editorial Team.

\section{IRB Information}

Shinshu University Ethics Committee (B0325).

\section{References}

1. Rubenstein L, Chun AK, Chew M, Binkert CA. Loop-snare technique for difficult inferior vena cava filter retrievals. $J$ Vasc Interv Radiol 2007; 18: 1315-1318.

2. Rana MA, Gloviczki P, Kalra M, Bjarnason H, Huang Y, Fleming MD. Open surgical removal of retained and dislodged inferior vena cava filters. J Vasc Surg Venous Lymphat Disord 2015; 3: 201-206.

\section{Supplementary Files}

Supplementary Movie. Retrieval of displaced inferior vena cava filter using loop-wire technique and dissection of the filter by a telescopic mechanical sheath set.

Please find supplementary file(s);

http://dx.doi.org/10.1253/circj.CJ-21-0164

Received February 25, 2021; revised manuscript received March 26, 2021; accepted April 9, 2021; J-STAGE Advance Publication released online May 26, 2021 Time for primary review: 22 days

Department of Cardiovascular Medicine, Shinshu University School of Medicine, Matsumoto (K.F., A.O., H.T., M.S., K.K.); Department of Cardiology, Tokyo Women's Medical University, Tokyo (M.S.), Japan

The first two authors contributed equally to this work (K.F., A.O.).

Mailing address: Morio Shoda, MD, PhD, Department of Cardiovascular Medicine, Shinshu University School of Medicine, 3-1-1 Asahi, Matsumoto 390-8621, Japan. E-mail: shoda.morio@ twmu.ac.jp

All rights are reserved to the Japanese Circulation Society. For permissions, please e-mail: cj@j-circ.or.jp

ISSN-1346-9843

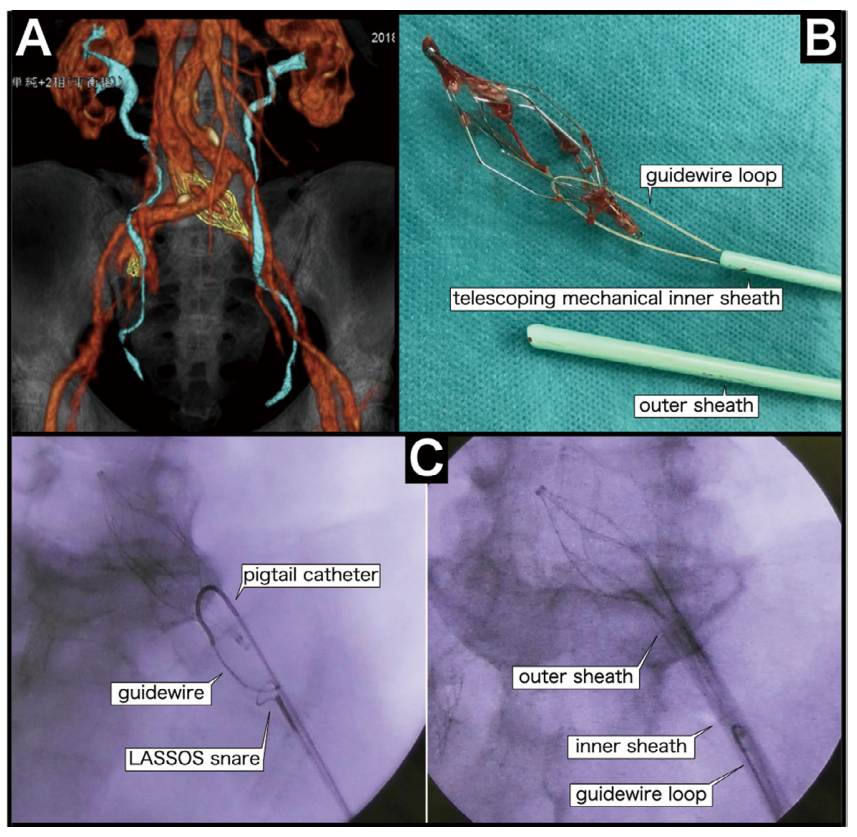

Figure. (A) 3D computed tomography of inferior vena cava filter displaced into the left common iliac vein. (B) The retrieved filter, looped wire, and specialized lead extraction sheaths. (C) The loop-wire technique (Left) and dissection of the filter by the telescopic mechanical sheath (Right). 